\title{
ATORES ANTROPÓFAGOS \\ PRÁTICA DE ENSAIO PARA UMA ATUAÇÃO POLIFÔNICA
}

Alvaro Bittencourt1

Mestre em Performance Teatral - Monash University/Austrália

alvarolevis@gmail.com

"Só a Antropofagia nos une. Socialmente. Economicamente. Filosoficamente. Única lei do mundo. Expressão mascarada de todos os individualismos, de todos os coletivismos".

Oswald de Andrade (1997. p. 353)

\section{ENTRADA...}

Um palco. Estruturas de futuras paredes, algumas cadeiras e um par de mesas. Um ator conversa com um preparador de elenco, um ensaiador. Ambos têm uma expressão profunda e apreensiva; ainda não acharam a forma correta de representar aquele trecho. 0 ator repete a cena, 0 preparador interrompe, eles conversam novamente. Essa sequência é repetida inúmeras vezes... Porém, súbitamente, embora o ator siga de forma precisa a mesma rotina de antes, algo se transforma em sua performance. Surge uma intensidade em seus movimentos que se conecta com seu tom de voz; suas mãos parecem tocar o ar que, agora, se torna mais denso em sua volta. "Isso!" grita o ensaiador animado. $\mathrm{O}$ ator se assusta e para. "Foi melhor?" Pergunta, esboçando um tímido sorriso. "Lógico que foi melhor! Foi muito bom! Você consegue repetir?" "Acho que sim..." diz o ator incerto do

\footnotetext{
${ }^{1}$ Alvaro Bittencourt - Mestre em Performance Teatral pela Monash University/Austrália (2010). Especialista em Metodologia das Ciências pela UNIBEM/PR (1997). Diretor, ator e professor de teatro, atua há trinta anos na cena curitibana. Seu foco de pesquisa é a prepação e direção de atores. Atualmente é integrante-fundador do Grupo de Teatro Ou Isto Ou Aquilo e professor de teatro da PUC/PR e nos Colégios SESI de Curitiba. Contato: alvarolevis@gmail.com.
} 
que acabou de fazer. Entretanto, ele repete os mesmos movimentos intensos, pronunciando o texto também intensamente. A expressão do preparador está visivelmente satisfeita. Ele não interrompe o ator desta vez; silenciosamente se aproxima e sussurra: "Continue a fazer exatamente o que você está fazendo, mas agora, diga o texto para a plateia...". O ator fica completamente perdido, toda força de suas intenções se esvai e sua performance é ainda pior do que no início do trabalho. Arrasado, o preparador olha para o auditório vazio e pensa: "Mas que confusão é essa que eu estou fazendo aqui?!".

A situação que acabei de descrever foi o preciso momento em que eu, o preparador de elenco acima, tive 0 "insight" do qual surgiu o embrião do projeto de pesquisa apresentado neste artigo. Naquele instante eu percebi quão contraditório era meu pedido àquele ator. Eu estava trabalhando com ele intensamente e por um longo período de tempo, utilizando um subtexto absolutamente realista. Então, repentinamente, eu pedi para que direcionasse sua atenção para a plateia, de forma a fazer um comentário distanciado sobre as circunstâncias da cena. Pode-se dizer que eu solicitei um desempenho brechtiano por meio de um método stanislavskiano. Não é de se estranhar que o ator ficasse confuso. Na verdade, sua tarefa consistia em modificar a perspectiva de atuação, porém eu solicitei a ele que operasse essa mudança sem discussão ou ensaio prévios. Alterações na forma de atuar são exigidas com frequência nas peças teatrais. Se considerarmos o panorama do teatro pósdramático então, essas mudanças podem transformar a partitura da performance num quebra-cabeça, como bem descreve Hans-Thies Lehmann:

... O teatro assume um caráter fragmentário e parcial. Ele renuncia o longo e incontestável critério de unidade e síntese e se abandona à sorte (e risco) de confiar nos impulsos individuais, fragmentos e micro-estruturas de textos de maneira a se tranformar num novo tipo de prática. (LEHMANN, 2006, p. 57)

A prática de ensaio descrita neste artigo leva em conta as diferentes demandas que o texto de uma peça, bem como a interpretação que o diretor dá ao mesmo, podem propor aos atores. Quando uso a expressão "diferentes demandas", estou me referindo a características estéticas que determinam expectativas particulares em relação à maneira através da qual os atores apresentarão seu texto para a plateia. O professor de interpretação Nick Moseley mantém que "estilos de interpretação são meramente sistemas de sinais, e que as performances existem mais para serem entendidas, que 
admiradas" 2 (MOSELEY, 2005, p. 196). Nesse sentido, minha intenção é facilitar a tarefa dos atores ao apresentar para a plateia um sistema de sinais específico enquanto representam determinado trecho de uma peça. A preparação do elenco, consequentemente, deve variar conforme os resultados pretendidos para cada trecho. Minha investigação objetiva contribuir com os atores na elaboração de seus papéis, focando diferentes perspectivas através das quais podem abordar as cenas de um texto dramático. Todo o trabalho em determinado trecho do texto é estruturado então, em relação a esta abordagem inicial.

Por meio desta prática de ensaio dirigi, em 2009, os atores Amelia Ducker, Michael Camilleri e Kate Dix na peça teatral Coming Home (Rientro a casa) de Franca Rame e Dario Fo, como parte integrante de minha tese de mestrado na Monash University, Austrália. $O$ espetáculo foi apresentado no Melbourne Fringe Festival e também no La Mama Theatre. Esse artigo se refere à metodologia empregada no processo de ensaio desta montagem.

\section{PRIMEIRO PRATO...}

\section{ATORES ANTROPÓFAGOS}

“Como 'comer', tendo também o tempo e a química para digerir os resultados dos demais? 0 'oposto' de uma cultura colonizada ou seduzida não é uma cultura que se isola, mas uma cultura que sabe cozinhar do seu modo e comer o que traz ou chega do exterior"

Eugenio Barba (1994,p. 29)

Tendo observado que, com o objetivo de atender às demandas dos textos ou encenações em que participam, os atores se utilizam de diferentes perspectivas de atuação, o primeiro e mais enigmático questionamento que minha pesquisa me propôs foi o de tentar compreender como os

\footnotetext{
2 Todas as traduções de citações em inglês que constam neste artigo foram relizadas pelo próprio autor.
} 
atores realizam essas adaptações ao representar. "Só não há determinismo onde há mistério" ${ }^{3} .0$ grande mistério, nesse caso, reside no fato de que essas mudanças de perpectiva frequentemente não são discutidas ou estudadas a priore nos processos de ensaio. Como já dizia Oswald de Andrade em seu Manifesto Antropófago "nunca admitimos o nascimento da lógica entre nós" 4.

Após algumas noites insones por conta deste questionamento, em uma tarde eu estava a caminho do "Centro de Pesquisa" da universidade, atormentado pela hercúlea tarefa de escrever algo consistente sobre meu projeto para apresentar aos meus orientadores na reunião que teríamos naquela semana. Durante esta caminhada tive um novo insight que pareceu esclarecer para mim o conceito "andradiano" de Antropofagia - o qual até então sempre me pareceu um pouco nebuloso. Os atores de alguma forma introjetam os conceitos a que estão expostos e os utilizam, de forma espontânea ao exteriozar sua interpretação da situação fictícia a ser representada! É a " transformação permanente do Tabu em totem"! 5 Ou seja, esses conceitos externos aos atores são "mixados" às influências culturais que absorveram e à memória de suas vivências pessoais; sendo que, posteriormente, esse "bolo alimentar" é apresentado para a platéia sob a forma de uma nova leitura, particular e, consequentemente, original. É "A experiência pessoal renovada" 6 pela assimilação de novos conceitos.

Essa introjeção, portanto, é uma assimilação, uma absorção, uma deglutição, uma devoração da criação do outro, do estrangeiro. Logo: Antropofagia.

A Antropofagia é um forte conceito artístico no Brasil até hoje, e como o poeta Augusto de Campos escreveu em 1975, "A Antropofagia [...] é também a única filosofia original brasileira e, sob alguns aspectos, o mais radical dos movimentos literários que produzimos" (CAMPOS, 1978, p. 124).

\footnotetext{
${ }^{3}$ Citação extraída do Manifesto Antropófago de Oswald de Andrade reproduzido na íntegra em TELES, Gilberto Mendonça. Vanguarda européia e modernismo brasileiro: apresentação dos principais poemas, manifestos, prefácios e conferências vanguardistas, de 1857 a 1972. 13ª ed. Petrópolis: Vozes, 1997.

${ }^{4}$ Idem.

5 Idem.

6 Idem.
} 
Sendo um brasileiro que recebeu a "vacina antropofágica" 7, que sofreu a influência desse conceito, senti-me inclinado a extendê-lo, de forma a aplicar a idéia ao teatro em geral, e ao trabalho do ator em particular. Adriano Bitarães Netto explica que "A Antropofagia, constitui-se assim, a partir de um duplo olhar: um para dentro do país outro para fora..." (BITARÃES NETTO, 2004, p. 16). No caso do ator, entretanto o foco duplo do olhar se daria para dentro e fora dele mesmo. Constitui-se dessa forma em uma atitude política perante seu próprio trabalho e as informações a que está sujeito.

Os praticantes de teatro estão constantemente "comendo" e "digerindo" uma grande variedade de conceitos artísticos, principalmente se considerarmos a velocidade dos meios de divulgação da informação atuais. "Caso se tente definir um modelo contemporâneo, irá se falar de cruzamentos, de mestiçagens, em suma de um 'teatro plural' que conjuga elementos heterogêneos" (ROUBINE, 2003, p. 202). Como resultado, uma diversidade de perspectivas sobre a atuação está sendo, consciente ou inconscientemente, utilizada pelos dramaturgos, e diretores de acordo com suas necessidades e objetivos artísticos. Sob estas circunstâncias, os atores precisam "comer", "digerir" e usar as influências a que estão expostos para atender à demanda dos dramaturgos e diretores. Seu trabalho deve se tornar compatível com este mundo artístico antropofágico.

Essa absorção de influências determina a incorporação artística de ideias e a combinação destas com conceitos próprios, cujos resultados serão revelados posteriormente para a plateia precisamente por meio dos recursos corporais dos intérpretes. Uma definição para o ator hoje, "no ano 456 da Deglutição do Bispo Sardinha" ", implica na possibilidade de absorver uma gama de diferentes conceitos de atuação. Os intérpretes teatrais contemporâneos precisam apresentar na sua performance a qualidade voraz de se apropriarem da obra artística ("Só me interessa o que não é meu." 9), precisam estar ávidos por devorar suas influências, devem estar constantemente "famintos"... são "atores antropófagos".

\footnotetext{
7 Idem.

8 Idem.

9 Idem.
} 


\section{SEGUNDO PRATO...}

\section{ESTRUTURA CONCEITUAL}

"Além disso, metáforas não são instrumentos meramente passivos que refletem a maneira que as pessoas pensam; elas são também e acima de tudo instrumentos ativos, porque produzem e reproduzem constantemente maneiras de pensar."

Giamprieto Gobo (2008, p. 300)

Intuitivamente concordando com o argumento de Gobo, eu utilizei a metáfora dos atores antropófagos, e do processo de digestão, para entender o trabalho dos atores em uma peça. Sendo assim, a minha compreensão foi que para o ator apresentar a sua leitura de um texto para o público, ele precisa "ingerir" e "digerir" esse texto. Minha intenção era desenvolver uma estrutura conceitual que pudesse guiar minha pesquisa prática, meu diálogo com o elenco e que também tivesse a possibilidade de se desdobrar em procedimentos baseados na minha experiência teatral, os quais pudessem contribuir para nosso trabalho conjunto. "É a escala termométrica do instinto antropofágico. De carnal, ele se torna eletivo e cria a amizade. Afetivo, o amor. Especulativo, a ciência" ${ }^{10}$. Considerando isto, eu visualizei o ator antropófago sentado a uma mesa, pronto para devorar a peça teatral, e vislumbrei três maneiras de abordar o texto nos ensaios.

A primeira forma de abordar a cena eu chamo de Abordagem Ver. Imagine os atores olhando para o prato de comida em frente a eles e perguntando: Que tipo de comida é esta? Quais alimentos fazem parte deste prato? Esta abordagem leva em consideração principalmente os elementos que compõem as circunstâncias de uma cena. O propósito é elaborar a performance dos atores focando no que o grupo"11 "vê" em um determinado trecho da peça, ou seja, como analisa esse trecho e a que

\footnotetext{
10 Idem.

11 Neste contexto, o significado do termo "grupo" é definido pelo conjunto colaborativo de artistas que participam do processo criativo durante os ensaios.
} 
relaciona o que está sendo analisado. O objetivo é encorajar o elenco a apresentar sua análise do texto para a plateia a partir de uma perspectiva distancianda, não orientada pelo ponto de vista dos personagens. "Mas acima de tudo 0 ator deve estar certo de que nenhum sentimento que valha a pena é enfraquecido quando trazido clara e criticamente a nível consciente" (BRECHT in WILLET, 1978, p. 101). Assim, ao trazer criticamente sentimentos à superfície da performance, os atores também permitem aos espectadores que reflitam sobre o que está sendo apresentado.

A segunda abordagem, Saborear, se relaciona ao momento em que os atores estão literalmente comendo a refeição: Qual é o sabor deste alimento? Quais ingredientes o compõem? Quais sensações são despertadas ao saboreá-lo? Por meio desta abordagem, os atores investigam o que sentiriam, e consequentemente, como reagiriam, ao realizar as ações sugeridas na cena. $A$ performance dos atores reflete motivações internas que são provocadas por ações físicas, pois, como observa Jean Benedetti ao refletir sobre o sistema de Stanislavski: "A emoção não pode ser evocada pela vontade. É o produto da ação" (BENEDETTI, 2005, p. 123). O objetivo, portanto, é fazer a platéia perceber a trajetória interna dos personagens em meio às circunstâncias propostas e, de certa forma, compartilhar seus sentimentos.

A terceira, a Abordagem Usar, considera o momento em que o alimento já foi digerido e se transformou em energia para produzir trabalho, ação. A questão agora é: Como o grupo irá usar esta energia? Essa abordagem se concentra, essencialmente, em como os artistas relacionam as circunstâncias da cena com experiências pessoais. Emprestando, um dos termos de Stanislavski, é possível dizer que, neste caso, os atores fazem uso da sua memória emocional para comunicar a cena para a plateia. De acordo com Grotowski, "Ritual é performance, uma ação realizada, um ato. Peças, shows, espetáculos são rituais degenerados" (SLOWIAK, 2007, p. 80). Portanto, por meio desta abordagem, os atores pretendem que os espectadores participem como testumunhas do ritual representado no palco.

Na minha forma de ver, essas abordagens representam três diferentes maneiras de estimular a sensibilidade dos atores e motivar sua criatividade. A utilização dessa metáfora permite questionar de que forma as situações apresentadas em um texto teatral podem impactar os atores, levando em conta a perspectiva através da qual eles as percebem. Esta divisão considera o modo como os atores 
abordam uma cena e, em consequência disso, como preparam sua performance e apresentam-na para a plateia.

Esta classificação pode ser, de certa forma, relacionada às forças motivas interiores definidas por Stanislavski: mente, sentimentos e vontade. No entanto, ele fazia uso das mesmas como componentes de um único sistema que vinha de encontro aos seus objetivos artísticos. Minha proposição visa, de maneira diversa, a acentuação proposital de uma dessas forças, segundo uma intenção particular, preliminarmente determinada pelas exigências do texto ou da montagem.

Com esta estrutura conceitual em mente e guiado por minha experiência, eu selecionei alguns procedimentos que considerei apropriados para cada uma dessas três abordagens. Estes procedimentos foram aplicados ao primeiro experimento do meu projeto de pesquisa: uma versão abreviada da peça pool (no water) de Mark Ravenhill, apresentada no teatro da Monash University. Desta forma, pude fazer uso das "habilidades básicas para pesquisa qualitativa" (LEAVY citando SALDAÑA, 2009, p. 136), espontaneamente desenvolvidas durante meus anos de prática teatral, para experimentar esses procedimentos. Os que se mostraram efetivos, compuseram três sequências de procedimentos que se transformaram na parte principal do processo de ensaio de Coming Home.

\section{PRATO PRINCIPAL...}

\section{A PRÁTICA}

"O espírito recusa-se a conceber o espírito sem o corpo."

Oswald de Andrade (1997, p. 355)

O texto de Coming Home tem um formato bastante dinâmico e errático, que simula 0 pensamento humano. Na peça, Caterina Mariani - em nossa montagem representada por três atores está no ápice de uma crise em seu casamento e expõe ao público, de uma forma narrativa, a difícil situação por que está passando. Essa narração é interrompida repetidamente pela apresentação de 
situações que viveu e por reconstruções críticas ou fantasiosas dessas situações. Considerando isto, a Abordagem Ver foi aplicada para os trechos da peça em que Catarina fala diretamente com a plateia de forma a narrar fatos que viveu - o "momento agora" como chamávamos nos ensaios - ou quando ela rememora algo através de uma perpectiva crítica. A Abordagem Saborear foi empregada quando Catarina revisita um evento com se estivesse tendo um "flashback". E a Abordagem Usar foi utilizada em trechos onde a personagem evoca fatos de sua vida a partir de uma perspectiva estereotipada, ou quando uma representação de seus desejos emerge na narrativa. Levando em consideração esses parâmetros para aplicar as abordagens, eu dividi o texto em dezoito seções, e designei uma das três abordagens para cada um desses trechos. Isso resultou em uma tabela (fig. 1) que definiu objetivos para os ensaios, bem como um cronograma de atividades. Estabelecer esta tabela de trabalho é um procedimento fundamental desta prática.

\begin{tabular}{|c|c|c|c|}
\hline \multicolumn{4}{|c|}{ TABELA DE TRABALHO - COMING HOME } \\
\hline SEÇÃO & AÇÃO & TEMPO & ABORDAGEM \\
\hline Introdução & $\begin{array}{l}\text { Explosão da crise de Caterina's / } \\
\text { Ônibus }\end{array}$ & $\begin{array}{l}\text { Primeia noite / } \\
\text { Segunda noite }\end{array}$ & Usar \\
\hline 1 & Procurando a casa & Segunda noite & Saborear \\
\hline \multirow{3}{*}{2} & Procurando a casa (continuação da seção 1) & Segunda noite & Saborear (Amelia) \\
\hline & Sub-seção / O Triturador de Mãos & Atemporal & Usar (Amelia/Michael) \\
\hline & O pico da crise se inicia & Momento agora & Ver (Kate) \\
\hline 3 & Descrevendo a relação sexual & Momento agora & Ver \\
\hline $4 a$ & Confronto com o marido - Carregando combustível & Primeia noite & Ver \\
\hline $4 b$ & Confronto com o marido - Chega! & 6:38 da manhã & Saborear \\
\hline $4 c$ & Confronto com o marido - Eu vou te envergonhar! & 6:38 da manhã & $\begin{array}{l}\text { Saborear (Kate) } \\
\text { Usar (Amelia/Michael) }\end{array}$ \\
\hline \multirow{2}{*}{5} & O míssil - Motores ligados & 6:38 da manhã & Usar (Kate) \\
\hline & Confronto com o marido (continuação da Seção 4) & 6:38 da manhã & Saborear (Amelia/Michael) \\
\hline 6 & O míssil - Decolagem & 6:38 da manhã & Usar \\
\hline \multirow[t]{2}{*}{7} & Procurando a casa (continuação da seção 1) & Segunda noite & Saborear \\
\hline & Confronto com o marido (continuação da Seção 4) & 6:38 da manhã & Saborear \\
\hline 8 & Seduzida pelo Triturador de Mãos em um bar & Manhã - antes do trabalho & Ver \\
\hline
\end{tabular}

Figura 1 - Acima, parte da tabela de trabalho de Coming Home com a divisão em seções e abordagens utilizadas. Note que muitas vezes as seções foram posteriormente subdivididas para a utilização de diferentes abordagens. 
Durante o primeiro experimento de minha pesquisa, observei que se tornava bastante confuso para os atores trabalhar por meio de diferentes abordagens em um mesmo ensaio. Uma vez que eles se preparavam para seguir determinados procedimentos, era mais produtivo continuar usando os mesmos procedimentos durante todo o ensaio. Assim, tornou-se um requisito central da metodologia que fosse utilizada, sempre que possível, apenas uma abordagem em cada dia de ensaio. Isso signifiva muitas vezes ensaiar cenas que não eram subsequentes no texto, mas que foram designadas para uma mesma abordagem. Como resultado, a divisão apresentada na tabela acima acabou também determinando o planejamento geral de ensaios da peça.

Abaixo, eu descrevo a sequência de procedimentos que foram empregados nos ensaios para cada abordagem. Ao final deste artigo, apresento uma pequena sequência de fotos, que podem ilustrar brevemente o trabalho desenvolvido por meio cada abordagem.

\section{$\underline{A B O R D A G E M ~ V E R}$}

Passo 1: Leitura Inicial - Todas as abordagens começavam com uma leitura sem interrupções da respectiva seção. Eu orientava o elenco a ler devagar, prestando o máximo de atenção ao texto com o objetivo de compreeder suas falas, e a anotar qualquer dúvida para ser discutida posteriormente. Fora isso, nada era sugerido ou solicitado aos atores durante este procedimento.

Passo 2: 0 que você vê nesta cena? - A leitura inicial era seguida por um longo debate que podia levar mais de uma hora. O foco do debate era levantar o que o grupo "via" na cena, ou seja, o grupo analisava o trecho em questão sob um ponto de vista externo (não orientado pela perspectiva da personagem), identificando relações e objetivos estabelecidos pelos personagens na situação apresentada. Esta análise fazia também um paralelo das circunstâncias da cena com a realidade, pois os integrantes do grupo reportavam situações que haviam testemunhado relacionadas àquela apresentada no texto. Em suma, a intenção do debate era discutir o texto da seção entendendo-o como um "evento construído" (Orr, p. 154) que se originou de uma percepção crítica da realidade. 
Passo 3: 0 que você vê em sua mente? - Como um terceiro passo, eu solicitava ao grupo que descrevesse imagens que vieram às suas mentes estimuladas pelo debate. Estas imagens não precisavam seguir nenhum padrão ou ligação lógica com a seção. Por meio deste questionamento, eu buscava descobrir o que o exercício racional da discussão havia despertado na sensibilidade e criatividade dos atores. Estas ideias eram anotadas por mim e esta lista era guardada para trabalho posterior.

Passo 4: Leitura com interrupções - A seção era lida várias vezes e a leitura interrompida repetidamente, num esforço de aplicar às falas os tópicos levantados na discussão. Dependendo da cena, eu também propunha aos atores que aplicassem uma dinâmica específica ao dizer o texto. Esta dinâmica era ligada a uma intenção dominante que eu antevia que poderia colaborar com a cena.

Passo 5: Trabalho físico com as imagens - Esse trabalho dependia dos resultados atingidos nos três passos anteriores. Analisando as imagens listadas no passo 3, os pontos principais levantados no debate e a performance dos atores na leitura, eu sugeria diferentes tarefas ao elenco. Propunha uma imagem - acordada pelo grupo como a mais marcante para ser usada como cenário imaginário; ou sugeria que utilizassem esta imagem como um meio de determinar uma ação básica a ser executada durante a seção; ou propunha ainda que experimentassem construir fisicamente várias das imagens listadas, de forma a identificar algo instigante para compor a cena. Às vezes, mais de uma opção era utilizada no ensaio.

Passo 6: 0 que acontece na cena? - Esse passo era utilizado nas três abordagens com 0 objetivo de ajudar o grupo a memorizar o conteúdo das falas em conjunto. Não seria possível ao elenco executar as ações sugeridas no próximo passo mantendo o texto à mão - prática frequentemente utilizada em ensaios teatrais. Portanto, neste momento, os atores faziam uma pausa do trabalho físico para estudar o texto até que se sentissem suficientemente seguros para improvisar o conteúdo das falas em sequência. Nesse ponto do processo, não havia qualquer preocupação com a precisão em relação às palavras do texto, mas sim com 0 conteúdo das falas. Os atores estudariam posteriormente as falas em casa, tendo em mente o trabalho realizado no ensaio. 
Passo 7: Adaptação das imagens às falas - As ações criadas, e selecionadas, no passo 5 eram agora executadas novamente e lentamente rearranjadas para se adequar às falas. Da mesma forma, o ritmo e pausas das falas eram adaptadas às ações. Durante este estágio, eu trabalhava em conjunto com os atores, interrompendo e solicitando repetições de forma a colaborar com as alterações e ajustes necessários.

Passo 8: Acomodação - Nas três abordagens, o último passo era uma execução integral da seção. Se uma ou duas interrupções fossem necessárias, eu ajudava os atores a resolver 0 problema e então eles seguiam em frente até o final da seção. Depois disso, eu fazia comentários, e, dependendo do resultado atingido, podia solicitar uma segunda execução do trecho sem interrupções.

\section{ABORDAGEM VER}

O grupo em trabalho de mesa abaixo. Ao lado, a imagem de um filme de Coppola que foi utilizada no ensaio da seção 8

- "Seduzida pelo Triturador de Mãos em um bar."
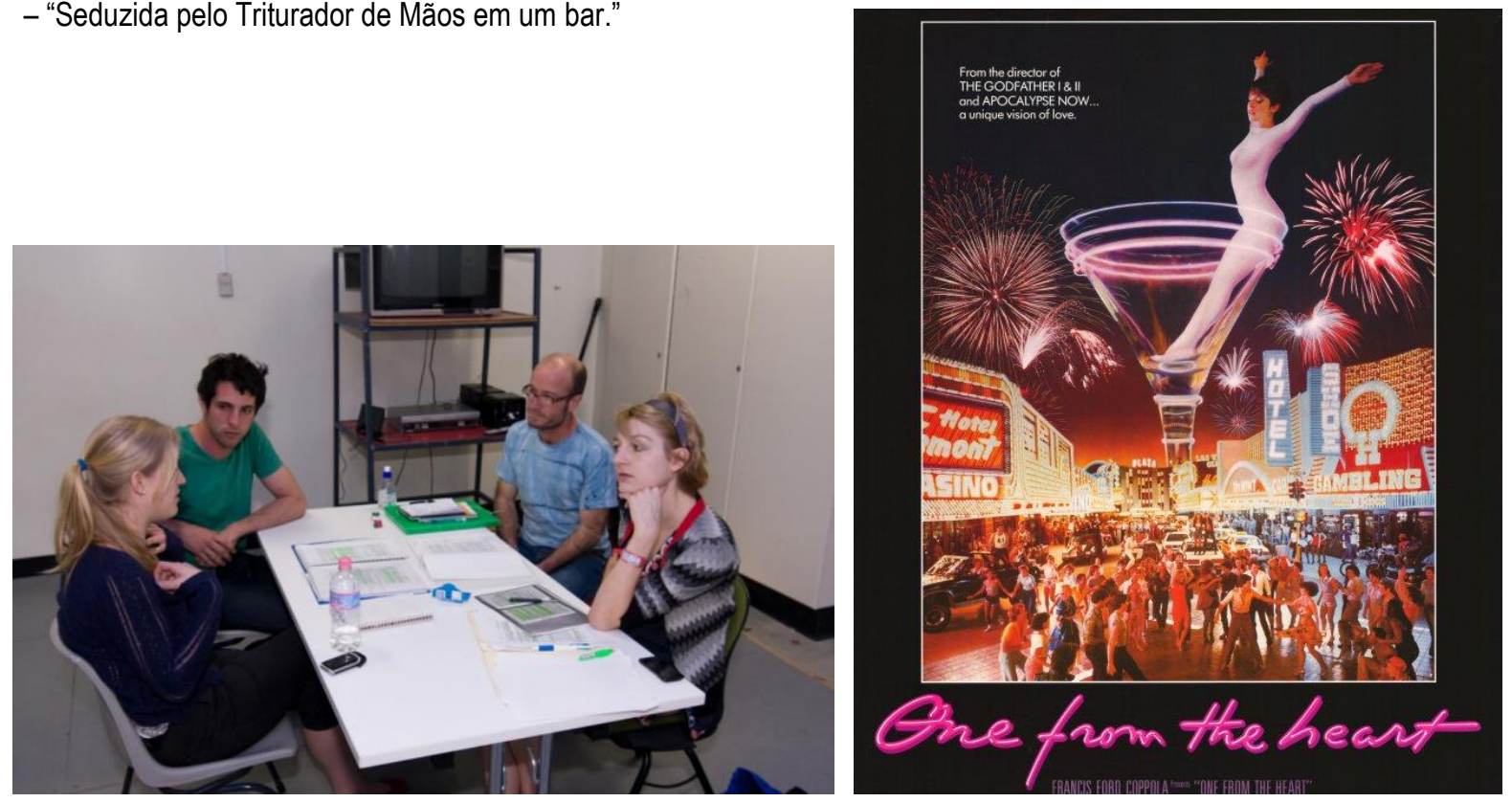

Abaixo, ainda no ensaio da seção 8, os atores bebem da enorme taça ilustrada pela imagem acima. Ao lado a mesma cena durante 0 espetáculo. 

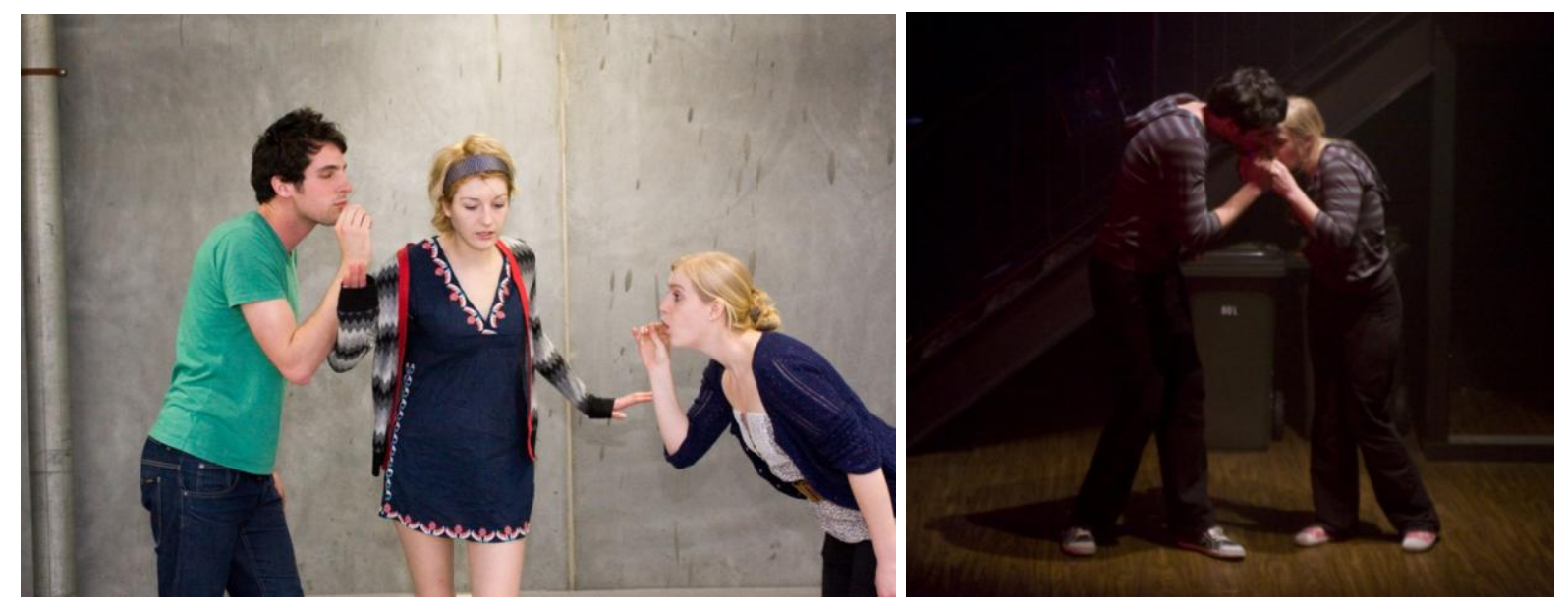

Fonte: Fotos: Tárcio Saraiva

\section{ABORDAGEM SABOREAR}

Passo 1: Leitura inicial - Idem à Abordagem Ver.

Passo 2: Lista das ações físicas - Uma relação meticulosa das possíveis ações físicas sugeridas pelo texto era escrita, delineando, dessa forma, um roteiro para a seção.

Passo 3: Improvisação - Os atores executavam a sequência de ações físicas, improvisando suas falas livremente. A eles era solicitado que executassem cada ação acuradamente e em tempo real, com a intenção de experienciá-las com profundidade. Por essa razão, esse passo frequentemente era bastante demorado, principalmente se comparado ao tempo que se pretendia que a cena durasse no espetáculo.

Passo 4: Leitura - Imediatamente após a improvisação, e sem nenhuma discussão, os atores faziam uma nova leitura sem interrupções da cena. Eu solicitava ao elenco que tentasse transferir para essa leitura as intenções, sentimentos e emoções experienciados no momento em que executaram as ações físicas. Invariavelmente, esta leitura da seção mostrava-se completamente diferente da inicial e emprestava muito mais sentido ao texto.

Passo 5: Leitura com interrupções - A seção era lida novamente, agora fazendo-se diversas interrupções, com o propósito de entender, reforçar e adequar as intenções 
reveladas na leitura anterior. Esta leitura era repetida duas ou três vezes. Nesta abordagem, a leitura com interrupções demandava um trabalho muito menos intenso do que na Abordagem Ver.

Passo 6: 0 que acontece na cena? - Idem à Abordagem Ver.

Passo 7: Síntetizando as ações para se adequarem às falas - Eu sugeria um "re-arranjo" sintético das ações, e os atores as executavam agregando a elas suas falas. De forma similar à Abordagem Ver, eu trabalhava em conjunto com os atores, parando nos momentos que necessitavam ajustes e colaborando com seu trabalho. Meu objetivo nesse passo era manter apenas as ações indispensáveis e, se possível, apenas frações essenciais das mesmas. As ações mimadas eram descartadas. Como resultado obtínhamos gestos que eram alusões às ações físicas originais e que os atores utilizavam para ilustrar a história que a personagem estava narrando. Esses gestos mantinham, entretanto, as intenções e a intensidade das ações físicas improvisadas.

Passo 8: Acomodação - Idem à Abordagem Ver.

\section{$\underline{A B O R D A G E M ~ S A B O R E A R}$}

No ensaio da seção 2 - "Procurando a casa" -, Amelia Ducker improvisa ações físicas. Enquanto Kate Dix (ao fundo), se prepara para entrar em cena por meio da Abordagem Ver.
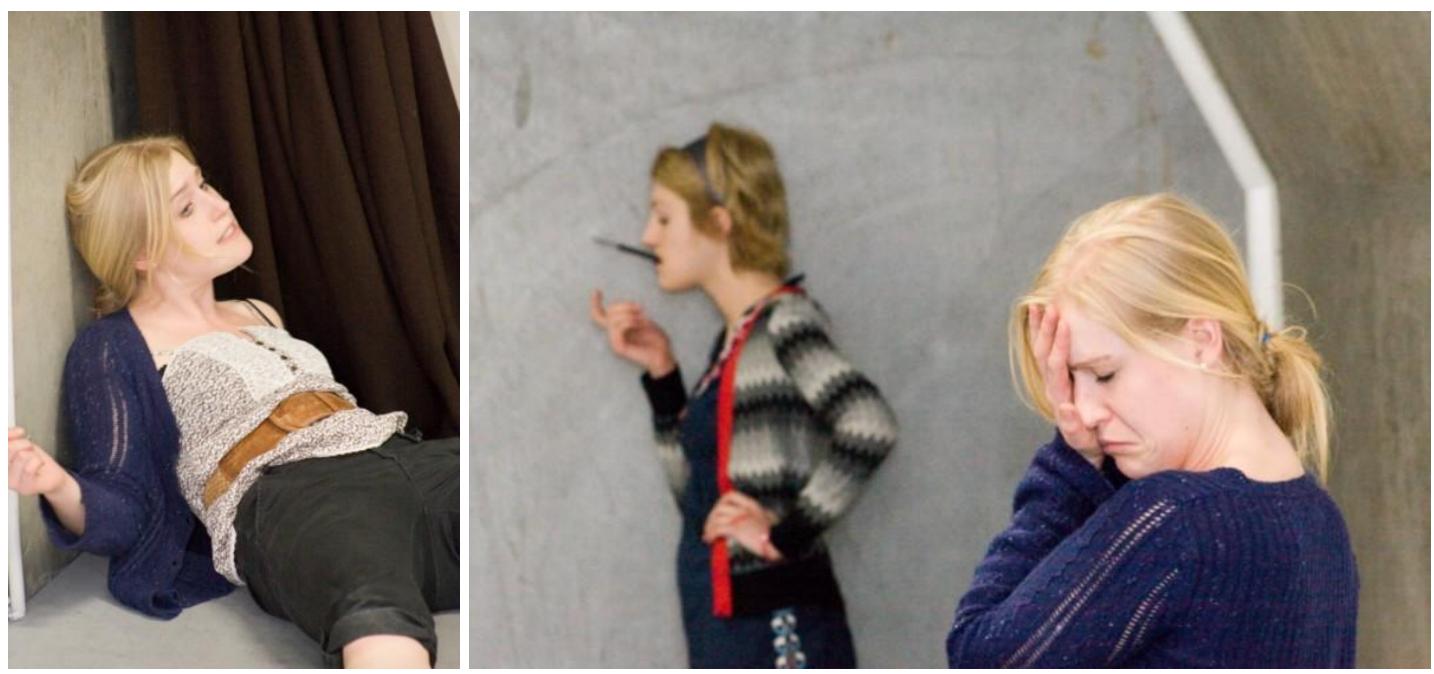
A seção 4b, "Confronto com o marido - Chega!", encenada através da Abordagem Saborear, em ensaio abaixo, e durante o espetáculo ao lado.
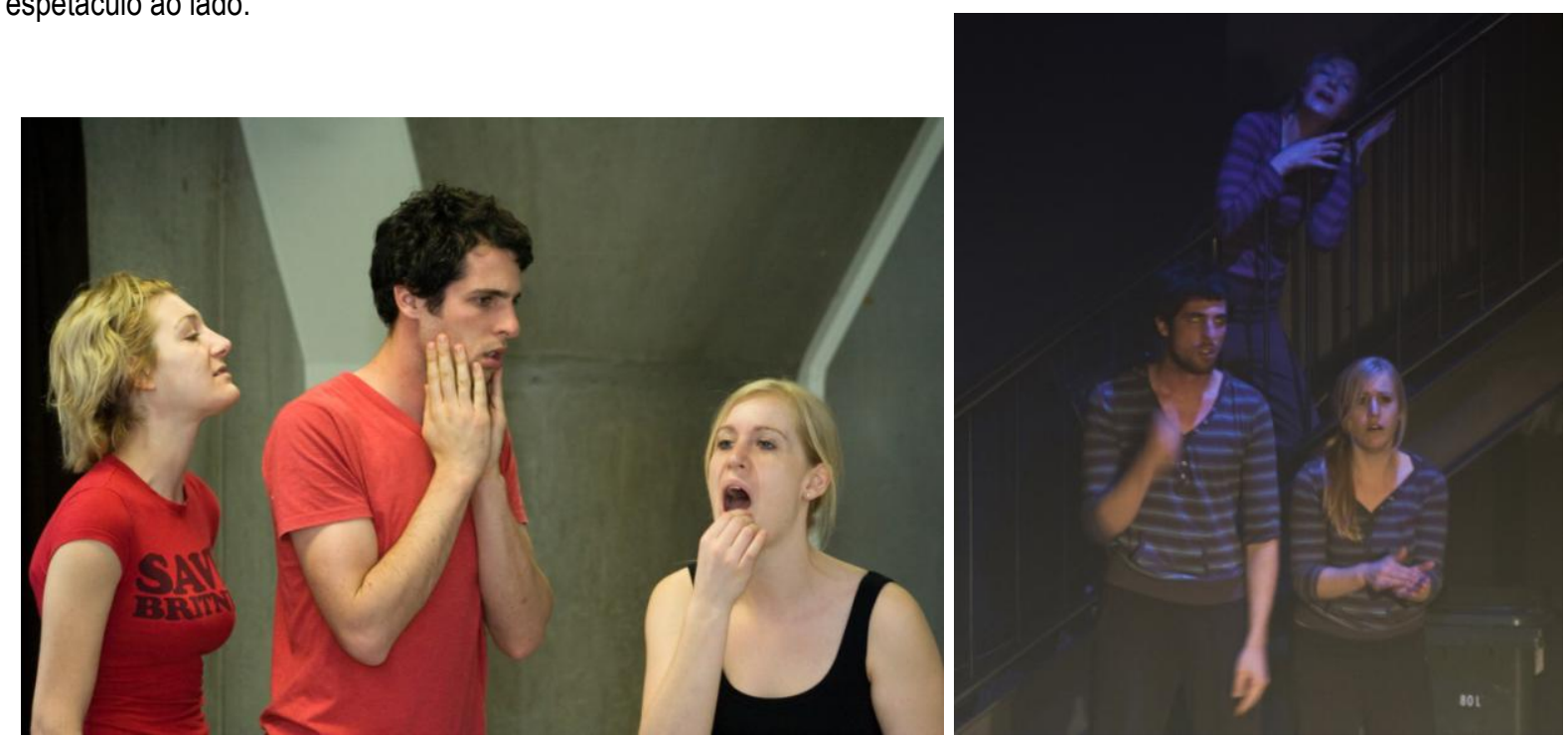

Fotos: Tárcio Saraiva

\section{ABORDAGEM USAR}

Passo 1: Leitura inicial - Idem às Abordagens Ver e Degustar.

Passo 2: Situações pessoais / desejos / situações imaginárias - A seção era debatida usando o formato de um "brainstorm", durante o qual o grupo era estimulado a descrever experiências pessoais que se relacionassem à situação apresentada na cena. Depois disso, eu solicitava que o elenco descrevesse desejos que o debate havia despertado. Eventualmente, eu também pedia que criassem situações imaginárias estimuladas de alguma forma pelo debate.

Passo 3: Roteiro e improvisação - Assim que o debate acabava, eu avaliava o que havia anotado e propunha uma improvisação inspirada nas situações mais estimulantes levantadas no debate. Durante esta improvisação, o elenco não precisava utilizar elementos do texto que estava sendo trabalhado, os intérpretes improvisavam livremente a partir do roteiro sugerido. 
Passo 4: Leitura - Como na Abordagem Saborear, era solicitado aos atores que fizessem uma nova leitura sem interrupções da seção. 0 intuito era empregar nessa leitura as intenções, sentimentos e emoções experienciados durante a improvisação, os quais emprestavam sentido e intensidade ao texto original.

Passo 5: Leitura com interrupções - uma nova leitura com inúmeras paradas era realizada, objetivando ajustar as intenções experienciadas durante a improvisação às falas da seção. Esta leitura era repetida várias vezes para que os atores ficassem seguros sobre a execução dos ajustes sugeridos.

Passo 6: 0 que acontece na cena? - Idem às Abordagens Ver e Degustar.

Passo 7: Adaptação das ações às falas - Utilizando a improvisação realizada como base, eu propunha uma adaptação de suas ações objetivando adequá-las às falas. Como resultado, num estado de percepção que relaciono ao que Shannon Rose Riley chama de "polifonia perceptiva" (RILEY, 2004, p. 467), o elenco trabalhava com duas diferentes sequências de ação: as ações físicas providas pela improvisação e as ações implícitas às falas do texto. Ou seja, as ações físicas funcionavam como uma ilustração, como uma estilização do texto da peça. Evidentemente, era necessário interromper os atores em vários momentos para fazer ajustes. Neste ponto do ensaio, eu trabalhava lentamente em conjunto com os atores para harmonizar a seção.

Passo 8: Acomodação - Idem às Abordagens Ver e Degustar. 


\section{ABORDAGEM USAR}

O elenco improvisa um carnaval, abaixo e ao lado, durante ensaio da seção 6 - "O míssil - Decolagem".
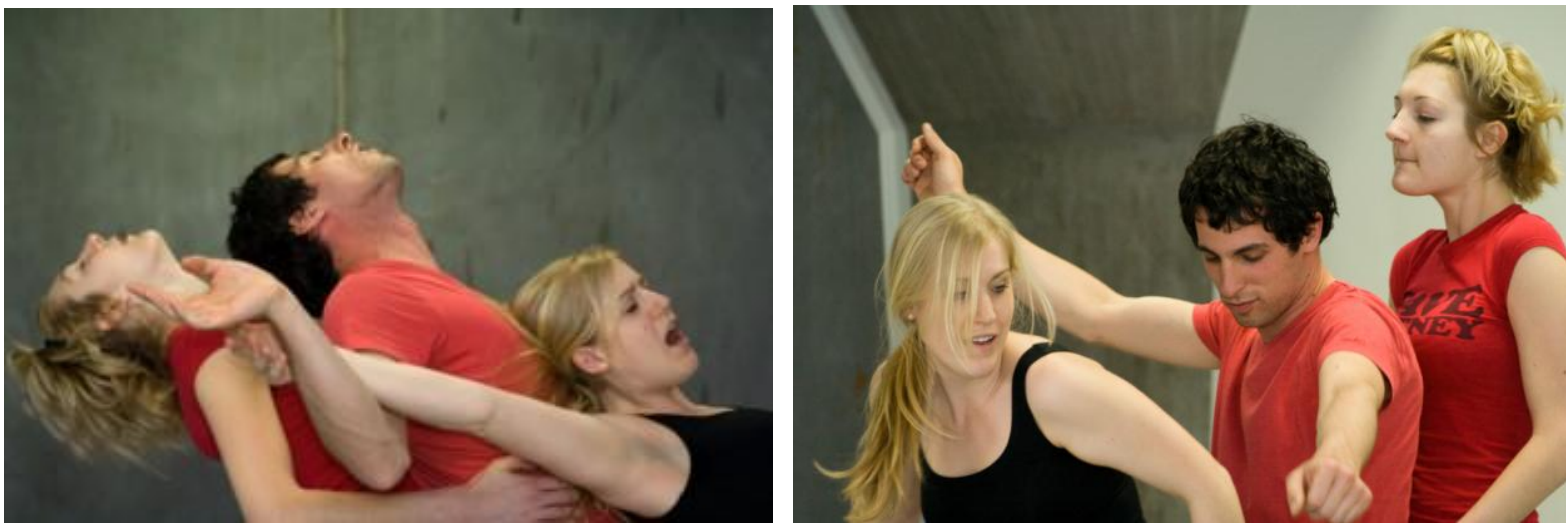

Abaixo, Michael Camileri e Amelia Ducker improvisam durante ensaio da a seção 4c : "Confronto com o marido - Eu vou te envergonhar!".
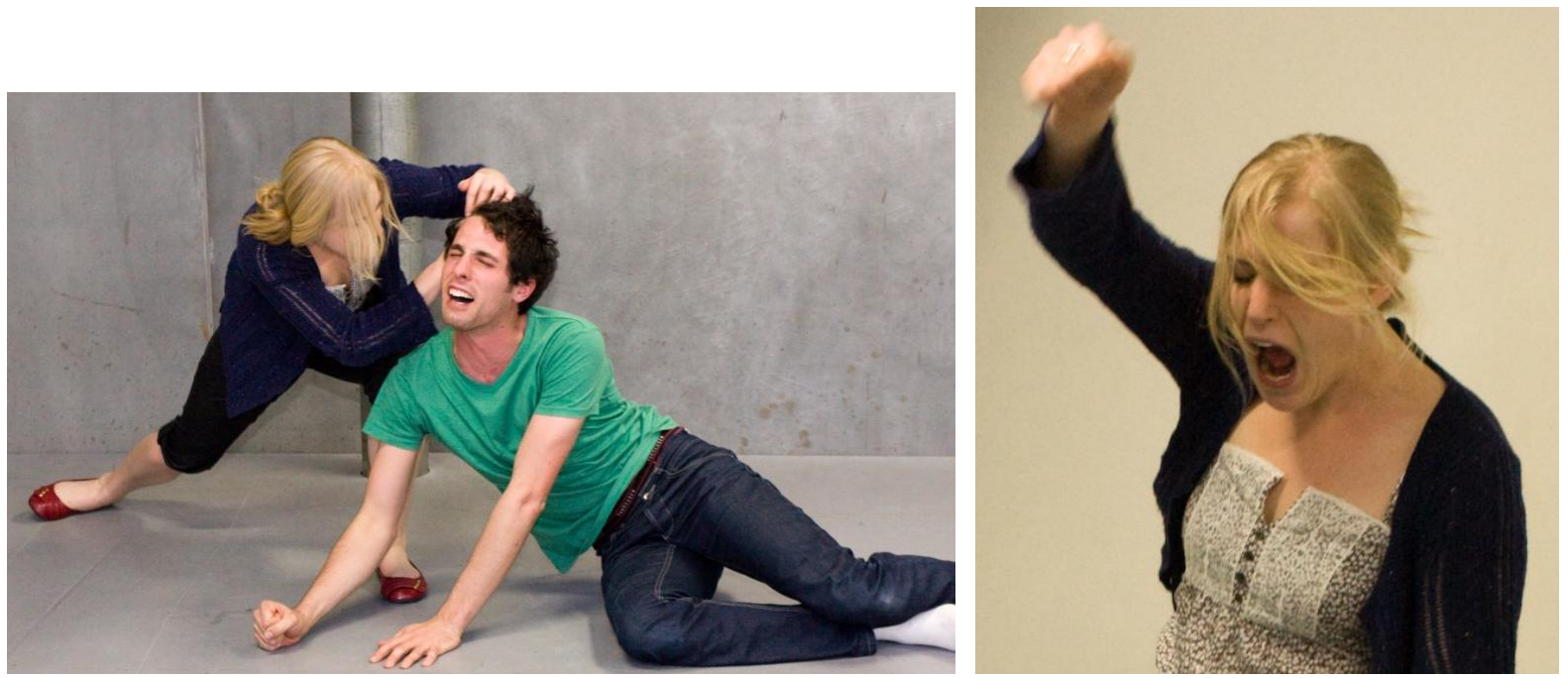

Fotos: Tárcio Saraiva

Após aplicar uma das abordagens a uma seção do texto, eu normalmente sugeria uma conecção com a cena anterior para tornar possível a representação de todas as seções já trabalhadas em sequência. Apresento abaixo uma tabela comparativa dos passos utilizados nas três abordagens. 


\begin{tabular}{|c|c|c|c|}
\hline passo & ABORDAGEM VER & ABORDAGEM DEGUSTAR & ABORDAGEM USAR \\
\hline 1 & \multicolumn{3}{|c|}{ Leitura inicial } \\
\hline 2 & O que você vê nesta cena? & Lista das ações físicas & $\begin{array}{c}\text { Situações pessoais / desejos / } \\
\text { situações imaginárias } \\
\end{array}$ \\
\hline 3 & O que você vê em sua mente? & Improvisação & Roteiro e improvisação \\
\hline 4 & Leitura com interrupções & Leitura & Leitura \\
\hline 5 & Trabalho físico com as imagens & Leitura com interrupções & Leitura com interrupções \\
\hline 6 & \multicolumn{3}{|c|}{ O que acontece na cena? } \\
\hline 7 & Adaptção das imagens às falas & $\begin{array}{c}\text { Sintetizando as ações para se adequarem } \\
\text { às falas }\end{array}$ & Adaptação das ações às falas \\
\hline 8 & \multicolumn{3}{|c|}{ Acomodação } \\
\hline
\end{tabular}

Figura 2 - Tabela comparativa dos procedimentos utilizados nas três abordagens.

Como fica claro na tabela acima, os passos 1, 6 e 8 são iguais nas três abordagens. As diferenças principais residem nos passos 2 e 3. A estrutura principal da Abordagem Ver é constituída pelo trabalho de mesa, durante o qual emergem imagens, relações entre os personagens são reveladas e intenções são esclarecidas. Esses fatores em conjunto constituem a motivação para 0 trabalho que será desenvolvido na cena. No caso das Abordagens Saborear e Usar entretanto, a base do trabalho é uma improvisação. A essência das intenções e relações entre os personagens são revelados pelo trabalho prático. Entretanto como afirma Elia Kazan "a ironia é que improvisação precisa de estrutura" (KAZAN, 2009, p. 261). A estrutura para a improvisação na Abordagem Saborear, é provida pelas ações físicas propostas pelo roteiro da peça. Elas abrem para os atores a possibilidade de compreender emocionalmente 0 trajeto que os personagens traçam em determinado trecho do texto. Todavia, na Abordagem Usar, o relato de experiências vividas pelos atores relacionadas à cena estabelece uma espécie de "memoria afetiva" - utilizando o conceito de Stanislavski - que os permite empregar uma leitura emocional específica ao texto. Como resultado, eles representam a cena com um alto nível de personalização (MCINTYRE, 2009, p 11). 


\section{SOBREMESA...}

Se entendermos um texto dramático como um grupo de ideias que tem o potencial de se desdobrar em ação no palco, é possível afirmar que o ponto de partida de um processo de ensaio é o texto. Levando isso em consideração, os atores podem trilhar os seguintes caminhos para abordar um determinado trecho deste texto: "ler" o texto e representar o que eles entendem que o dramaturgo propõe (Abordagem Saborear); "lê-lo" criticamente e atuar informado por essa análise do texto (Abordagem Ver); ou "ler" o trecho relacionando-o a experiências pessoais, e utilizar essas experiências como um meio para expressar o texto (Abordagem Usar). As abordagens que proponho neste artigo, portanto, levam em conta a perspectiva através da qual os atores percebem as circunstâncias que compõem as cenas de uma peça teatral. Obviamente, estas três diferentes maneiras de abordar um trecho de um texto dramático influenciam o resultado que os atores atingem e, como consequência, o modo como apresentam este determinado trecho para a plateia. Neste sentido, a prática aqui descrita propõe um estilo de atuação "polifônico" e, sob meu ponto de vista, tal flexibilidade se adequa melhor a um panorama de teatro pós-dramático.

Para que a prática de ensaio que proponho seja efetiva, os atores devem ter uma atitude similar à de um elenco fixo, de um "ensemble" e, consequentemente, devem estar "preparados para negociar tudo no espaço de ensaio e não em suas próprias cabeças" (MOSELEY, 2005, p. 195). Uma característica fundamental desta prática reside no fato de que todos os papeis devem ser entendidos como construções colaborativas. Isto significa que uma personagem não será compreendida como uma composição a ser elaborada isoladamente pelo ator em relação ao texto. Um papel, ao contrário, passará a ser uma criação de um grupo de atores que estão em relação um com o outro, sob a orientação de um diretor. Consequentemente nesse caso, um comportamento representado no palco só será crível sob as as circunstâncias dadas pela leitura particular a que o grupo colaborativo chegou em conjunto, enquanto trabalhava determinado trecho do texto.

A estrutura conceitual desenvolvida nesta pesquisa estabelece uma linguagem, um vocabulário a ser compartilhado na sala de ensaio. O fato de que a comunição do grupo foi 
"equalizada" pelo mesmo vocabulário estimulou a participação do elenco na discussão, no estudo, e conseqüentemente, na elaboração do trabalho. Esta linguagem de ensaio facilitou o meu diálogo como pesquisador e diretor da peça - com os atores, assim como promoveu uma compreensão global do processo. Por meio desta linguagem comum, eu pude fazer com que os atores estivessem cientes de qual abordagem era aplicada para cada seção do texto, quais passos deveriam ser seguidos para aplicar a respectiva abordagem, e qual era o objetivo de cada passo aplicado. Como resultado, enquanto atuava nos ensaios, o elenco memorizou, através da repetição, como representar cada trecho da peça de acordo com a abordagem empregada. A confiança que os atores foram ganhando durante o ensaio das seções, também fez com que as transições entre essas diferentes maneiras de representar fossem sendo gradualmente executadas com mais facilidade por eles. Eu observei que, durante as apresentações do espetáculo, os intérpretes mudavam confortavelmente de uma forma de atuar para outra sem perder a intensidade de suas performances. Mais ainda, sob meu ponto de vista essas alterações na atuação eram, em vários momentos da peça, impactantes para a plateia.

A grande maioria das ações que o elenco representava no espetáculo foram desenvolvidas por meio das abordagens descritas neste artigo; estas ações foram criadas inteiramente dentro da sala de ensaio pelo grupo colaborativo de trabalho. Por esta razão, todas as sequências fixadas para compor as cenas da peça, acabaram se tornando algo mais abrangente do que aquilo que normalmente no teatro chamamos de "marcação". A marcação é frequentemente entendida como uma sequência de ações determinada pelo diretor para uma determinada cena e que deve ser memorizada pelo elenco. No caso do processo de ensaio aqui relatado, os atores desenvolveram fortes ligações internas com as ações que representavam, uma vez que elas eram provenientes de improvisações conectadas ao trabalho de criação seus papeis. Provavelmente devido a esse fato, as ações eram executadas intensamente desde o início do trabalho em cada seção, e a performance dos atores manifestava, na minha opinião, um alto nível de engajamento. A prática experienciada induziu a uma incorporação das ações - no sentido físico e interno - que se refletiu em toda a performance.

No caso de Coming Home, essas ações altamente personalizadas foram, na maioria das vezes, suficientes por si só para apresentar as cenas para os espectadores e acabaram por constituir a marcação final do espetáculo. A prática aplicada resultou numa performance intensamente física, na qual o elenco utilizava suas habilidades corporais para ambientar as cenas. Nesse sentido, é possível 
dizer que os atores "desenhavam", por meio de suas próprias perfomances, os cenários nos quais eles atuavam. Isso representou uma descoberta definitiva para o meu trabalho como diretor, pois formatou uma metodologia para elaborar uma performance baseada exclusivamente nos recursos expressivos dos atores, e isso sintetiza o estilo de direção que venho buscando desenvolver.

Eu acredito que a combinação de dois fatores, a conscientização sobre o processo de ensaio e as conecções internas estabelecidas com as ações, proporcionou ao elenco uma estrutura que lhes deu confiança para representar. A significância dessa prática de ensaio reside, portanto, no fato de que ela provê uma base concreta para elenco atuar. Embora, no caso deste estudo, a prática proposta tenha definido todo o processo de ensaio da peça, eu creio que a mesma metodologia possa também ser empregada como uma ferramenta. Relaciono isto à minha experiência como ensaiador de elenco. Muitas vezes me vi sozinho com um grupo de atores sem saber por onde iniciar o trabalho de forma a realizar as solicitações do diretor. Através dessa prática de ensaio pode-se trabalhar com os atores na elaboração de seus papeis sob o ponto de vista das demandas da cena em questão. Isso vem de encontro à intrincada tarefa que um preparador de elenco enfrenta numa montagem. $\mathrm{O}$ diretor solicita que ele ensaie separadamente, com um ou mais atores, determinada cena que por alguma razão não está "funcionando". Frequentemente, é bastante difícil identificar o que está causando o problema. "Se nós [atores] temos clareza sobre aquilo que deve ser feito, podemos fazê-lo sem pensar, e no momento de fazê-lo, torna-se natural por nenhuma outra razão a não ser pelo fato de termos consentido em fazêIo" (MOSELEY, 2005, p. 27). Portanto, a melhor maneira de enfrentar o desafio acima é reforçar as bases do trabalho de forma a clarificar para os atores o que deve ser feito e reforçar a incorporação dos aspectos básicos daquela trecho do texto. Ao se sentirem seguros sobre a estrutura na qual estão atuando, os atores tendem a se sentir seguros para realizar as tarefas mais elaboradas da encenação.

Na Abordagem Ver, esta estrutura é composta por uma análise abrangente do texto e por um consistente trabalho de leitura. Por outro lado, uma meticulosa sequência de ações físicas é o passo central que formula a base para a Abordagem Saborear. Na Abordagem Usar, contudo, a estrutura básica é desenvolvida principalmente a partir de uma improvisação relacionada à memória emocional dos atores. Eu acredito fortemente que essas três estruturas básicas, as quais permitem aos atores fundamentar sua relação com o texto dramático, e como consequência, incorporar um trabalho 
detalhado de atuação, são a principal contribuição que esta prática pode proporcionar a preparadores de elenco e diretores que tem o desafio de lidar com a complexa e sutil tarefa de dirigir atores.

\section{REFERÊNCIAS}

ANDRADE, Oswald de. "Manifesto antropófago". In: TELES, Gilberto Mendonça. Vanguarda européia e modernismo brasileiro: apresentação dos principais poemas, manifestos, prefácios e conferências vanguardistas, de 1857 a 1972. 13ª . ed. Petrópolis: Vozes, 1997.

BARBA, Eugenio. A Canoa de Papel: Tratado de Antropologia Teatral. Trad. Patrícia Alves. São Paulo: Hucitec, 1994.

BENEDETTI, Jean. The Art of The Actor. London: Methuen, 2005.

BITARÃES NETTO, Adriano. Antropofagia Oswaldiana: Um Receituário Estético e Científico. São Paulo: Annablume, 2004.

BITTENCOURT, Alvaro. Anthropophagous Actors: a Polyphonic Rehearsal Practice. MA (Theatre Performance) thesis. Melbourne: Monash University, 2010.

CAMPOS, Augusto de. Poesia antipoesia antropofagia. São Paulo: Cortez \& Moraes, 1978.

GOBO, Giampietro. Doing Ethnography. Sage, Los Angeles/London/New Delhi/Singapore: 2008.

KAZAN, Elia. Kazan on directing. New York: Alfred A. Knopf, 2009.

LEAVY, Patricia. Method meets arts: arts-based research practice. New York/London: The Guilford Press, 2009.

LEHMANN, Hans-Thies. Postdramatic Theatre. Trans. Karen Jurs-Munby. London; New York: Routledge, 2006. 
MCINTYRE, Marilyn. "What Is Personalization?" Back Stage 50.21( 2009): 11. Web.11 Jan. 2010.

MOSELEY, Nick. Acting and Reacting: Tools for the Modern Actor. London: Nick Hern Books, 2005.

ORR, Shelley. "Teaching Play Analysis: How a key dramaturgical skill can foster critical approaches". Theatre Topics 13.1 (2003): 153-158. Web. 11 Jan. 2010.

RAME, Franca e Dario Fo. "Coming Home". In: A Woman Alone \& Other Plays. Emery and Christopher Cairns (ed.). Trad. Gillian Hanna. London: Methuen Drama, 1991.

RAVENHILL, Mark. pool (no water) / Citizenship. London: Methuen Drama, 2007.

RILEY, Shannon Rose. "Embodied Perceptual Practices: Towards an Embrained and Embodied Model of Mind for Use in Actor Training and Rehearsal". Theatre Topics 14.2 (2004): 445-71. Web. 11 Jan. 2010.

ROUBINE, Jean-Jacques. Introdução às Grandes Teorias do Teatro. Trad. André Telles. Rio de Janeiro: Jorge Zahar Editor, 2003.

SLOWIAK, James and Jairo Cuesta. Jerzy Grotowski. London/New York: Routledge, 2007.

STANISLAVSKI, Constantin. A Preparação do Ator. Trad. Pontes de Paula Lima. Rio de Janeiro: Civilização Brasileira, 1986.

WILLET, John (ed. e trad). Brecht on Theatre. London: Eyre Methuen, 1978. 